Document downloaded from:

http://hdl.handle.net/10251/64314

This paper must be cited as:

Martí Vargas, JR.; García Taengua, EJ.; Serna Ros, P. (2013). Influence of concrete composition on anchorage bond behavior of prestressing reinforcement. Construction and Building Materials. 48:1156-1164. doi:10.1016/j.conbuildmat.2013.07.102.

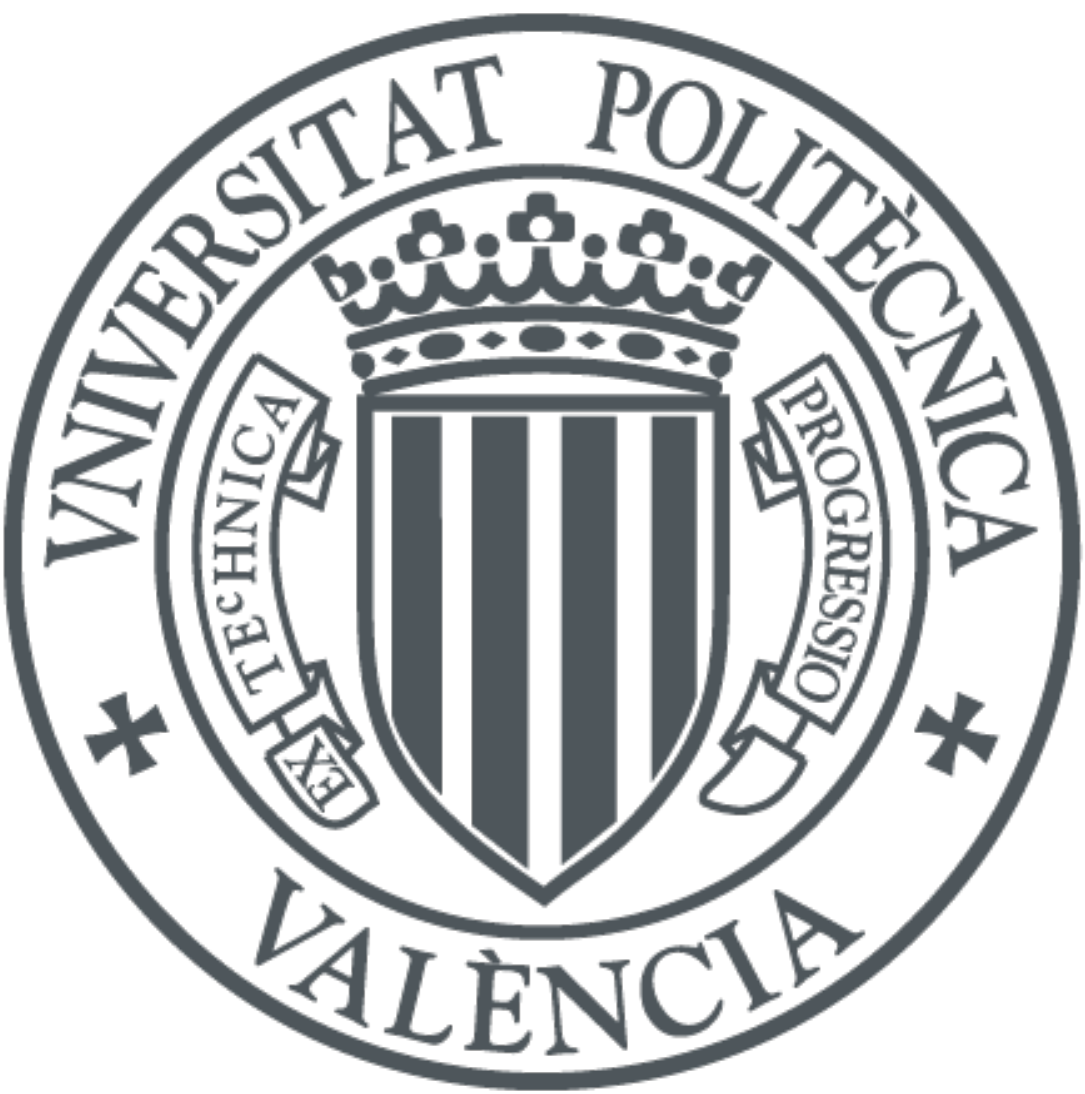

The final publication is available at

http://dx.doi.org/10.1016/j.conbuildmat.2013.07.102

Copyright Elsevier

Additional Information 


\title{
1 Influence of concrete composition on anchorage bond behavior of
}

\section{2 prestressing reinforcement}

\author{
J.R. Martí-Vargas*, E. García-Taengua, P. Serna
}

ICITECH, Institute of Concrete Science and Technology

Universitat Politècnica de València, 4G, Camino de Vera s/n, 46022, Valencia, Spain

e-mail address: jrmarti@cst.upv.es; $\underline{\text { emgartae@ upv.es; pserna@cst.upv.es }}$

e-mail address: jrmarti@cst.upv.es (José R. Martí-Vargas)

\section{ABSTRACT:}

An experimental research addressing the effects of concrete composition and strength on anchorage bond behavior of prestressing reinforcement is presented to clarify the effect of material properties that have appeared contradictory in previous literature. Bond stresses and anchorage lengths have been obtained in twelve concrete mixes made up of different cement contents (C) -350 to $500 \mathrm{~kg} / \mathrm{m}^{3}$ - and water/cement (w/c) ratios -0.3 to $0.5-$, with compressive strength at 24 hours ranging from 24 to $55 \mathrm{MPa}$. A testing technique based on measuring the prestressing force in specimens with different embedment lengths has been used. The results show that anchorage length increases when w/c increases, more significantly when $\mathrm{C}$ is higher; the effect of $\mathrm{C}$ reveals different trends based on w/c. The obtained anchorage bond stresses are greater for higher concrete compressive strength, and their average ratio of 1.45 with respect to transmission bond stresses implies a potential bond capacity. KEYWORDS: 


\section{INTRODUCTION}

In pretensioned prestressed concrete, prestressing reinforcement stresses vary along the member length and through time. Two main stages must be considered - prestress transfer and loading- which require setting up two lengths [1]: transmission length (transfer length [2]), defined as the distance along which the prestress is built up in the prestressing reinforcement after prestress transfer, and anchorage length (development length [2]), defined as the distance required to transfer the ultimate tension force to the concrete. Fig. 1 illustrates these lengths and the idealized profile of the prestressing reinforcement force at the end of a member.

Estimation of transmission and anchorage lengths from the required bond stress is important in design [3]. Different experimental methodologies to characterize bond and to determine transmission and anchorage lengths have been proposed based on push-in test [4], pull-out test [5,6], push-pullout test [7], reinforcement end slip [8], and longitudinal concrete strain [9]. However, no consensus exists regarding a standard testing method for bond properties analyses [15,16].

As exposed in the background section, and particularly concerning the effect of concrete composition variations, additional knowledge about bond behavior of prestressing

\footnotetext{
${ }^{1}$ ECADA is the Spanish acronym for "Ensayo para Caracterizar la Adherencia mediante Destesado y Arrancamiento"; in English, "Test to Characterize the Bond by Release and Pull-out".
} 
reinforcement is required for a better determination of transmission and anchorage lengths in

51 precast pretensioned concrete members.

Regarding transmission length, a first study on the effects of concrete composition was carried out at the Institute of Concrete Science and Technology at Universitat Politècnica of València [17]. In this context, and as a complementary part of that first study, the purpose of this paper is to present the experimental results addressing the effects of concrete composition on anchorage bond behavior of seven-wire prestressing strands. To this end, an experimental program to determine anchorage lengths, as well as the average bond stress along these lengths in twelve concretes of different composition -varying cement contents and with different water-to-cement (w/c) ratios- and properties, by means of the ECADA test method, 61 has been carried out.

\section{BACKGROUND}

64

Bond strength, as well as transmission and anchorage lengths, are function of a large numbers of factors [1]: concrete strength at the time of the prestress transfer, initial reinforcement stress, concrete cover, prestress transfer procedure, reinforcement size and geometry, surface condition, concrete strength at the time of loading, etc. The mechanisms associated with bond are still being studied [18]. Several equations to calculate both transmission and anchorage lengths have been proposed $[3,19]$. However, no consensus has been reached concerning the main parameters to be considered in these equations. Some authors and code provisions for anchorage length propose equations in which concrete properties are not a parameter [2,20].

73 Only concrete compressive strength is included when concrete properties are considered 
76 Several experimental works about bond and transmission, and on anchorage lengths of prestressing reinforcement, have been conducted over the years. There have been different and conflicting observations about the effect of important parameter on anchorage length in previous literature. Regarding concrete compressive strength, several authors $[21,23,24]$ have concluded that transmission and anchorage lengths decrease when concrete compressive strength increases. Furthermore, [25] points out that the influence of concrete compressive strength on bond capacity of prestressing reinforcement is not clear.

Cement content and w/c ratio are important parameters of the concrete mix design.

Nevertheless, few studies [26,27] have been undertaken regarding their influence on bond properties. According to [26], bond strength decreases when the w/c ratio increases. However, according to [27] bond strength improves when the w/c ratio increases. On the other hand, bond strength has been found to be higher when cement content is increased [26], whereas other authors [28] have concluded that increasing cement content produces a reduction of bond strength.

The aforementioned first study [17] showed that the influence of w/c ratio on transmission length is very small for concretes with low cement contents, but the influence of w/c ratio was highly significant when cement content is high. Also, the effect of cement content on transmission lengths revealed different tendencies based on w/c ratio.

Recent studies on the effects of varying concrete composition on bond properties have focused on self-compacting concrete [29,30], ultra-high strength concrete [31], and steel fiber reinforced concrete [6]. 
101 On the other hand, in addition to the anchorage length definition in terms of stress (or force)

$102[1,2]$, the maximum stress in the prestressing reinforcement must be achieved by preventing

103 reinforcement end slip [32]. However, a limitation or an account for reinforcement slip is not

104 addressed in the main design codes $[2,33,34]$.

105

106 Consequently, researchers have suggested defining anchorage length based on two different

107

108

109

110

111

112

113

114

115

116

117

118

119

120

121

122

123

124 assumptions [35]: without prestressing reinforcement slip at the free end of the member during the loading stage (anchorage length -without slip-, $L_{A}$ ), and accepting prestressing reinforcement slips at the free end when a prestressed concrete member is loaded (anchorage length with slip, $L_{S}$ ). These two anchorage length modes have been considered in this experimental study.

\section{EXPERIMENTAL STUDY}

\subsection{Test equipment and instrumentation}

The ECADA test method $[12,36]$ has been used in this experimental study. This test method is based on the measurement of the prestressing reinforcement force at a simulated cross section of a pretensioned prestressed concrete member. To this end, a prestressing frame is required to test specimens as a part of one end of the member, as shown in Fig. 2. An adjustable reinforcement anchorage is placed at one end (free end) of the prestressing frame to facilitate the tensioning and release operations- and an Anchorage-Measurement-Access (AMA) system at the other end (stressed end). The AMA system serves as anchorage for the prestressing reinforcement, it simulates the sectional rigidity of the specimens, it allows the 
measurement of the prestressing reinforcement force, and it allows to increase the prestressing

126 reinforcement force by pull out. A detailed description of the test method and the AMA system requirements is available in $[12,36]$.

129 The test equipment is completed with a hollow hydraulic jack of $300 \mathrm{kN}$ of capacity that can

130 be placed at each end of the prestressing frame. The force in the reinforcement is controlled at

131 all times during the test by means of a hollow force transducer HBM C6A located in the

132 AMA system. A pressure transducer completes the instrumentation and is used to control the

133 hydraulic jack. No internal measuring devices are used in the specimens tested in order not to

134 interfere bond phenomena.

136 As a complement for this experimental study, a displacement transducer at the free end of the specimen is used allowing the prestressing reinforcement end slip to be measured during

138 loading. Therefore, according to the two anchorage length modes, the criterion to determine

$139 L_{A}$ is based on the force achieved immediately before prestressing reinforcement end slip

140 occurs, and only the prestressing reinforcement force achieved is considered in determining $141 L_{S}$

\subsection{Specimen testing procedure}

145 This test method allows the characterization of bond of prestressing reinforcement in concrete

146 by means of the sequential release of the prestress transfer (detensioning) and the pull-out

147 (loading) operation on the same specimen test. Testing a specimen consists of the following

148 stages: preparation, prestress transfer (release), and anchorage capacity (loading) analysis, as

149 follows. 
151 Preparation stage:

152 - Alignment of the reinforcement in the prestressing frame.

153 - Reinforcement tensioning by means of the hydraulic jack which is coupled at the free 154 end of the frame.

155 - Anchoring of the reinforcement by means of the adjustable anchorage; the hydraulic 156 jack is relieved (and it can be coupled to other frame for a new operation).

157 Casting of the specimen: concrete is mixed, placed into the moulds in each frame, and 158 consolidated; specimens remain under the selected conservation conditions until the 159 time of prestress transfer.

Prestress transfer stage:

- Release: the hydraulic jack is remounted on the free end and the adjustable anchorage is removed; the hydraulic jack is gradually unloaded, triggering the transfer of the actual prestressing force $\left(P_{0}\right)$ to concrete.

- Measuring: the prestressed concrete specimen is supported at the end plate of the prestressing frame included in the AMA system; the hydraulic jack is relieved; after a stabilization period, the prestressing reinforcement force $\left(P_{T}\right)$ is measured.

Loading stage:

- Preliminary: the hydraulic jack is anew coupled to the frame at the stressed end; a displacement transducer is placed at the free end of the test specimen. hydraulic jack which pulls the AMA system from the pretensioning frame. 
- Measuring: the maximum force achieved during the pull-out operation before reinforcement slip at the free end $\left(P_{A}\right)$ and the maximum force achieved during the pull-out operation $\left(P_{S}\right)$ is measured. Testing is complete when the prestressing reinforcement fractures, the concrete splits, or there is reinforcement slippage without reinforcement force increase.

\subsection{Transmission and anchorage lengths determination}

With the ECADA test method, the determination of transmission and anchorage lengths requires testing a series specimens with different embedment lengths. After the specimens have been tested, both the transmission and the anchorage lengths are determined by plotting the measured prestressing reinforcement forces -at the prestress transfer and loading stagesvs the specimen embedment length. Fig. 3 shows an idealization of what these plots look like.

For the transferred prestressing force values $\left(P_{T}\right)$, the curves are expected to present a bilinear trend (see Fig. 3), with an ascendent branch followed by a practically horizontal branch corresponding to the effective prestressing force $\left(P_{E}\right.$, maximum prestressing force value determined by strain compatibility between the prestressing reinforcement and concrete). The transmission length $\left(L_{T}\right)$ corresponds to the specimen embedment length that marks the beginning of the horizontal branch. As shown in Fig. 3, this is the point where $P_{T}=P_{E}$.

195 For the pull-out forces values $\left(P_{A}\right.$ and $\left.P_{S}\right)$, the curves are expected to show an increasing trend (see Fig. 3). A reference force $\left(P_{R}\right)$ was established to analyze the anchorage behavior. The anchorage length $\left(L_{A}\right)$ corresponds to the shortest embedment length among the tested specimens in which $P_{R}$ is achieved in the pull-out operation without reinforcement slip at the 
199 free end of the specimen, that is, to the first specimen of the series with $P_{A} \geq P_{R}$. The

200 anchorage length with slip $\left(L_{S}\right)$ corresponds to the shortest embedment length of the test

201 specimens in which $P_{R}$ is achieved in the pull-out operation, that is, to the first specimen of

202 the series with $P_{S} \geq P_{R}$.

203

204 3.4. Bond stress determination

205

206 Based on the uniform bond stress distribution hypothesis which is generally accepted by

207 several Codes $[2,33,34]$ and authors $[7,37,38]$, the average bond stress values are obtained by

208 balancing the prestressing reinforcement force with the resultant of induced bond stresses at

209 the different testing stages, as follows:

210

$211 \quad U_{T}=\frac{P_{E}}{\left(\frac{4}{3} \pi \phi\right) L_{T}}$

212

$U_{A}=\frac{P_{A}}{\left(\frac{4}{3} \pi \phi\right) L_{A}}$

213

$U_{S}=\frac{P_{S}}{\left(\frac{4}{3} \pi \phi\right) L_{S}}$

214 Where:

$215 U_{T}=$ average bond stress along the transmission length

$216 U_{A}=$ average bond stress along the anchorage length

$217 U_{S} \quad=$ average bond stress along the anchorage length with slip allowed

$218 P_{E} \quad=$ effective prestressing force

$219 P_{A} \quad=$ maximum force reached during the pull-out operation before reinforcement slippage 
$220 \quad P_{S} \quad=$ maximum prestressing reinforcement force anchored during the pull-out operation

$221 \phi \quad=$ nominal diameter of prestressing reinforcement

$222 \quad L_{T} \quad=$ transmission length

$223 L_{A} \quad=$ anchorage length

$224 L_{S} \quad=$ anchorage length with prestressing reinforcement end slippage

\subsection{Program}

Twelve concretes mixes with $\mathrm{w} / \mathrm{c}$ ratios ranging from 0.3 to 0.5 , cement contents from 350 to $500 \mathrm{~kg} / \mathrm{m}^{3}$ and compressive strength at the age of testing $f_{c i}$ from 24 to $55 \mathrm{MPa}$ have been tested. This range was selected as representative of most of the cases in precast prestressed concrete industry, as pointed out by the companies partaking in this study and according with the Spanish code provisions [39] for prestress transfer (concrete stress after prestress transfer must not exceed $\left.0.6 f_{c i}\right)$. Concrete components were: cement CEM I 52.5 R [40], crushed

234 limestone aggregate $7 / 12 \mathrm{~mm}$, washed rolled limestone sand $0 / 4 \mathrm{~mm}$ and a polycarboxylic 235 ether-based high range water reducer. All concrete mixes were designed with a constant 236 gravel/sand ratio of 1.14 .

238 The prestressing reinforcement used was low-relaxation, seven-wire steel strand of $13 \mathrm{~mm}$

239 nominal diameter. The strand had a guaranteed ultimate strength $1860 \mathrm{MPa}$, specified as

240 UNE 36094:97 Y 1860 S7 13.0 [10]. The manufacturer provided the following main

241 characteristics: diameter $12.9 \mathrm{~mm}$, section $99.69 \mathrm{~mm}^{2}$, nominal strength $192.60 \mathrm{kN}$, yield 242 stress at $0.2 \% 177.50 \mathrm{kN}$, and modulus of elasticity $196.70 \mathrm{GPa}$.

244 The testing parameters were: 
- Specimens were $100 \times 100 \mathrm{~mm}^{2}$ cross-sectioned (to avoid splitting failure) with a centered prestressing strand.

- Prestressing strands were tested in as-received conditions, free of rust and free of lubricant, and were not treated in any special way.

- The strand prestress level was of 75 percent of specified strand strength (maximum level of prestress according to the Spanish code provisions [39] for pretensioning).

- All specimens were subjected to the same consolidation and curing conditions, and they were conserved under laboratory conditions.

- The release was performed 24 hours after concreting gradually at a controlled speed of $0.80 \mathrm{kN} / \mathrm{s}$ (to simulate the gradual release method as used by the companies partaking in this study).

- The loading stage was also gradually performed after the stabilization period (2 hours in this study).

- Series of embedment lengths followed increments of $50 \mathrm{~mm}$.

- For the anchorage analysis, the pull-out loading was performed to achieve a reference force $\left(P_{R}\right)$ of $158 \mathrm{kN}$ which was established as representative in this experimental study of the force that can be applied to the strand before failure.

- The anchorage length $\left(L_{A}\right)$ was assumed for a strand slip of $0.1 \mathrm{~mm}$.

264 Some aspects of the experimental study are shown in Fig. 4: a specimen when casting (a), a general view of the prestressing frames (b) and some series of tested specimens (c). 
269 For each specimen, the prestress transfer and the pull-out operations performed by means of 270 the ECADA test method have been carried out sequentially following the same sequence of 271 operations in all cases. For each concrete mix, transmission length $\left(L_{T}\right)$ and anchorage lengths $272\left(L_{A}\right.$ and $\left.L_{S}\right)$ have been determined from a series made up of 6 to 12 specimens with different 273 embedment lengths.

Table 1 provides the main results for all the concrete mix designs, including concrete compressive strength at the age of testing, tested specimen embedment lengths, measured prestressing strand forces and obtained lengths. The effective prestressing force $P_{E}$ is the average value of the force in the prestressing strand in those specimens with an embedment length equal to or longer than the transmission length obtained by the ECADA test method for 280 each concrete mix design after the stabilization period. $P_{A}$ and $P_{S}$ values are the measured 281 values in the corresponding specimens.

As observed in Table 1, $L_{T}$ values range from 400 to $650 \mathrm{~mm}, L_{A}$ from 600 to $850 \mathrm{~mm}$, and $L_{S}$ 284 from 300 to $700 \mathrm{~mm}$. As reference values, transmission and anchorage lengths calculated 285 according to the 12-4 equation of ACI 318-11 [2] are provided. They are $810 \mathrm{~mm}-$ for 286 effective prestressing force of $130.8 \mathrm{kN}$, the average value for the analyzed concretes- and $2871320 \mathrm{~mm}$-for $158 \mathrm{kN}$, the $P_{R^{-}}$, respectively. These values do not depend on concrete 288 properties [2]. A reference value for $L_{S}$ is not available, because this length constitutes a new 289 concept and there is no equation for it in literature. Calculated lengths overestimate 290 experimental values between $125 \%$ and $200 \%$ in the case of $L_{T}$ and between $155 \%$ to $220 \%$ in 291 the case of $L_{A}$. 
As observed in Table 1, and according to the transmission and anchorage length definitions,

294 all $L_{A}$ values are greater than the corresponding $L_{T}$. However, it is worth noting that almost all

$295 L_{S}$ values are shorter than the corresponding $L_{T}$, and the difference between them is bigger

296 when concrete compressive strength is higher. This proves that higher bond stresses can be

297 achieved from the mechanical action exerted by developing strand end slip. In addition,

298 obtained $L_{A}$ values prove to be dependent on concrete properties and composition, and it is

299 remarkable that they are lower than the provided values according to ACI 318-11 [2]. An

300 overestimation of the measured anchorage lengths by ACI 318-11 provisions has also been

301 detected in other experimental studies [13,21].

303 Several studies have addressed the influence of parameters like concrete compressive

304 strength, strand diameter or bond strength. Some predictive equations to obtain the

305 transmission and anchorage lengths have been proposed $[3,19]$. However, no equations

306 involving concrete mix design parameters, such as w/c ratio or cement content are found in

307 previous literature. It was not the objective of this study to come to a new design equation, but

308 only to assess the influence of concrete composition on anchorage lengths.

310 The parameters w/c ratio, cement content, and concrete compressive strength have been

311 considered as separate parameters in the analyses carried out. These parameters are correlated

312 and they therefore constitute a multi-variable system, as can be observed in Fig. 5. The

313 obtained concrete compressive strengths for all concrete mixes are being related with w/c

314 ratio (Fig. 5a) and cement content (Fig. 5b). As expected, concrete compressive strength

315 decreases when w/c ratio increases. The slopes of the curves appear to be comparable in Fig.

316 5a. However, in Fig. 5b it appears different tendencies based on different free water contents

317 remaining in concrete after casting. It is worth noting that these correlations do not necessarily 
318 implies that the effects of concrete compressive strength, w/c ratio, and cement content on

319 anchorage bond behavior are also correlated or follow the same trends. This justifies to

320 perform separate analyses for each parameter.

322 The results of transmission length were presented and analyzed in [17]. The following

323 sections provide the discussion of the two modes of anchorage length. In addition, as the

324 transmission length is also part of the anchorage length, some analyses regarding the whole of results and their relations are also included.

\subsection{Influence of concrete compressive strength}

Fig. 6 shows the results of the anchorage length $\left(L_{A}\right)$ vs concrete compressive strength at the age of testing $f_{c i}$. The anchorage length decreases when $f_{c i}$ increases. The results are fitted to the linear tendency according to Eq. (6) with a $R^{2}=0.50$.

Fig. 7 provides the results of anchorage length with slip $\left(L_{S}\right)$ vs concrete compressive strength. It is observed that the higher concrete compressive strength is, the lower the $L_{S}$ values obtained. The results are fitted to a linear tendency according to Eq. (7) with a $R^{2}=$ 0.68 .

\subsection{Influence of $w / c$ ratio}


344 Fig. 8 shows the results of anchorage length $\left(L_{A}\right)$ vs w/c ratio. It is observed that the greater

345 the w/c ratio, the greater the anchorage length obtained. The results are fitted to the linear

346 trend according to Eq. (4) with a coefficient of correlation $\left(R^{2}\right)$ of 0.41 .

$L_{A}=916.2(w / c)+307.8$

Fig. 9 provides the results of anchorage length with slip $\left(L_{S}\right)$ vs w/c ratio. It is observed that anchorage length with slip is greater for greater w/c ratio. Scatter of results tends to increase when w/c ratio increases. The results are fitted to the linear trend according to Eq. (5) with a $R^{2}=0.53$

\subsection{Influence of cement content}

359 Fig. 10 provides the results of the anchorage length $\left(L_{A}\right)$ vs the cement content used in each concrete mix design. It can be observed that $L_{A}$ depends as much on cement content as on w/c ratio. If the w/c ratio is high $(0.50), L_{A}$ strongly increases when cement content increases; if

362 the w/c ratio is medium $(0.45-0.40), L_{A}$ slightly increases when cement content increases; and

363 if the w/c ratio is low $(0.35-0.30), L_{A}$ does not vary irrespectively of cement content increases.

364 Finally, it is observed that $L_{A}$ for concretes with $350 \mathrm{~kg} / \mathrm{m}^{3}$ cement content practically does not vary, irrespectively of w/c ratio. 
Fig. 11 shows the results of the anchorage length with slip $\left(L_{S}\right)$ vs the cement content used in

368 each concrete mix design. The tendencies observed are similar to those observed for $L_{A}$ : they depend as much on cement content as on w/c ratio, except for concretes with $350 \mathrm{~kg} / \mathrm{m}^{3}$ cement content, whose $L_{S}$ values practically coincide, irrespectively of the w/c ratio. For the rest of the concrete mix designs, $L_{S}$ strongly increases when cement content increases and the

372 w/c ratio is high (0.50); for the other w/c ratios (medium or low, 0.45-0.30), $L_{S}$ slightly

373 increases when cement content increases.

These tendencies for both $L_{A}$ and $L_{S}$ values agree with [28] when the w/c ratio is high: if cement content increases, bond capacity decreases, and the anchorage length increases. The influence of w/c ratios seems to be clear in concretes with high cement content and less obvious when cement content is low. It can be explained by the fact that free water remaining in concrete increases with the cement content, and then the influence of concrete porosity on bond behavior also increases [41]. As this is an effect related to the total free water, w/c ratios are more influent when cement content is high.

383 The obtained coefficients of correlation $\left(R^{2}\right)$, which range 0.41 to 0.68 for fitted lines in sections 4.1 and 4.2 are comparable to other studies on bond of prestressing strands by applying simple regression models [42] with $R^{2}$ ranging from 0.47 to 0.69 . However, from the analysis of influence of cement content, the results reveal different tendencies with respect to 387 w/c ratio and a fitted line has not been added because a general trend has not been observed.

\subsection{Bond stresses}


391 From the prestressing strand forces and anchorage lengths $\left(L_{A}\right.$ and $\left.L_{S}\right)$ measured, average

392 bond stresses $\left(U_{A}\right.$ and $\left.U_{S}\right)$ along both $L_{A}$ and $L_{S}$ have been obtained by using Eqs. (2) and (3),

393 respectively. Figs. 12 and 13 show the obtained bond stresses for each concrete mix design. In

394 addition to transmission length results were analyzed in detail in [17], Figs. 12 and 13 also

395 include the $U_{A} / U_{T}$ and $U_{S} / U_{T}$ ratios -and their average values- for comparison purposes,

396 where $U_{T}$ is the average bond stress along the transmission length according to Eq. (1). As it

397 can be observed in both figures, generally for same cement content, an increase in the average

398 bond stress is observed when w/c ratio decreases. For the case of the lower cement content

$399\left(350 \mathrm{~kg} / \mathrm{m}^{3}\right)$, the average bond stresses appears to be independent of w/c ratios.

400

$401 U_{A} / U_{T}$ values (Fig. 12) are of de order of 1 -average ratio is $0.96-$. However, the $U_{S} / U_{T}$ ratio

402 (Fig. 13) ranges from 1.13 to 1.78 , with an average value of 1.45 . This is because the

403 mechanical action exerted by developing strand slips increases bond strength along $L_{S}$

404 (anchorage length with slip) when compared to the bond strength along $L_{A}$ (anchorage length

405 -without slip-). This contribution can enhance the strength and ductility of pretensioned

406 members by improving their bond strength at the end zones after anchorage failure according

407 to $L_{A}$ occurs.

408

409

The effects of concrete compressive strength $\left(f_{c i}\right)$ on the average bond stresses $U_{A}$ and $U_{S}$ are shown in Fig. 14. It can be observed that both $U_{A}$ and $U_{S}$ values increase when concrete

411 compressive strength increases. For the same increase in $f_{c i}, U_{S}$ improvement is greater than

$412 U_{A}$ improvement. In this way, the $U_{S} / U_{A}$ ratio also increases when $f_{c i}$ increases. From test

413 results, $U_{S} / U_{A}$ ratios ranging from 1.15 to 1.93 with an average value of 1.52 have been 414 obtained. 
416 In this experimental study for the bond characterization of $13 \mathrm{~mm}$ prestressing steel strands,

417 the loading stage was performed 2 hours after the prestress transfer stage. This fact implies

418 that the concrete compressive strength at loading coincides with $f_{c i}$. For $\left[f_{c}\right.$ (at loading) $]>\left[f_{c i}\right.$

419 (at prestress transfer)], $U_{A}$ and $U_{S}$ values can be expected to be above the obtained values in

420 this study and to have the same tendencies. In order to obtain equations for design with $95 \%$

421 confidence intervals, additional experimental works on transmission and anchorage lengths

422 should be conducted.

\section{CONCLUSIONS}

The research program reported herein has analyzed the anchorage bond behavior and has determined the anchorage lengths of pretensioned prestressed concrete specimens in two modes: anchorage length $\left(L_{A}\right)$-without slip- and anchorage length with slip and $\left(L_{S}\right)$, and their corresponding average bond stresses $U_{A}$ and $U_{S}$. From twelve concrete mixes, with different cement contents and water/cement (w/c) ratios, specimens containing 13-mm seven-

431 wire prestressing steel strand were tested using the ECADA test method. The main

432 conclusions drawn from this experimental study are as follows:

- $L_{S}$ values are shorter than the corresponding transmission length $L_{T}$ values, mainly when

435 concrete compressive strength is higher. This proves that higher bond stresses can be 436 achieved due to the mechanical action exerted by the development of strand end slip.

- Anchorage lengths $L_{A}$ and $L_{S}$ decrease when concrete compressive strength at the age of

438 testing increases. However, this fact is not considered in the current ACI 318 Code

439 provisions, which are conservative when the results obtained in this study are taken into 440 account. 
- Anchorage lengths $L_{A}$ and $L_{S}$ increase when w/c ratio increases, more significantly when

442 cement content is higher.

443

- The effect of cement content reveals different tendencies with respect to w/c ratio:

- When cement content increases, $L_{A}$ strongly increases if w/c ratio is high (0.50), slightly increases if $\mathrm{w} / \mathrm{c}$ ratio is medium $(0.45-0.40)$, and does not vary if $\mathrm{w} / \mathrm{c}$ ratio is low $(0.35)$.

- When cement content increases, $L_{S}$ strongly increases if w/c ratio is high (0.50), and slightly increases if w/c ratio is medium or low $(0.45-0.35)$.

- For low cement content $\left(350 \mathrm{~kg} / \mathrm{m}^{3}\right), L_{A}$ and $L_{S}$ practically do not vary irrespectively of the w/c ratio.

- Except for low cement content $\left(350 \mathrm{~kg} / \mathrm{m}^{3}\right)$, an increase in the average bond stresses $U_{A}$ and $U_{S}$ is observed for same cement content when w/c ratio decreases.

- $U_{A}$ and $U_{S}$ as well as $U_{S} / U_{A}$ ratios increase when concrete compressive strength at the age of testing increases.

- $U_{S} / U_{T}$ values range from 1.13 to 1.78 , with an average value of 1.45 . This is because the mechanical action exerted by developing strand slips increases bond strength along $L_{S}$ (anchorage length with slip) when compared to the bond strength along $L_{A}$ (anchorage length -without slip-). This contribution can enhance the strength and ductility of pretensioned members by means a potential bond capacity at the end zones after anchorage failure according to $L_{A}$ occurs.

New results directly related to the influence of concrete composition on anchorage bond behavior of prestressing reinforcement have been presented in this paper. The conclusions obtained have pointed out that other aspects in addition to concrete strength can affect bond phenomena in pretensioned concrete. Regarding the reasons for the observed behavior, further 
researches should be addressed including experimental techniques to characterize concrete immediately surrounding the reinforcement-concrete interface.

\section{ACKNOWLEDGEMENTS}

470

471 The content of this article is part of the research that the Institute of Concrete Science and 472 Technology (ICITECH) at Universitat Politècnica de València is currently conducting in conjunction with PREVALESA and ISOCRON. This study has been funded by the Ministry of Education and Science/Science and Innovation and ERDF (Projects BIA2006-05521 and BIA2009-12722). The authors wish to thank the aforementioned companies as well as the technicians at the concrete structures laboratory of the Universitat Politècnica de València for their cooperation. Finally, the authors wish to pay their respects to C.A. Arbeláez.

\section{REFERENCES}

481 [1] FIB. Bond of reinforcement in concrete. Bulletin d'information $n^{\circ} 10$. Lausanne:

482 Fédération Internationale du Béton; 2000.

483 [2] ACI Committee 318. Building code requirements for reinforced concrete (ACI 318-11).

484 Farmington Hills, MI: American Concrete Institute; 2011.

485 [3] Martí-Vargas JR, Serna P, Navarro-Gregori J, Pallarés L. Bond of $13 \mathrm{~mm}$ prestressing

486 steel strands in pretensioned concrete members. Eng Struct 2012;41:403-412.

487 [4] Rose DR, Russell BW. Investigation of standardized tests to measure the bond

488 performance of prestressing strand. PCI J 1997;42:56-80.

489 [5] Moustafa S. Pull-out strength of strand and lifting loops. Technical Bulletin 74-B5.

490 Washington: Concrete Technology Corporation; 1974. 
[6] Baran E, Akis T, Yesilmen S. Pull-out behavior of prestressing strands in steel fiber

492 reinforced concrete. Constr Build Mater 2012;28:362-371.

493 [7] Hegger J, Bülte S, Kommer B. Structural behavior of prestressed beams made with self494 consolidating concrete. PCI J 2007;52(4):34-42.

495 [8] Martí-Vargas JR, Arbeláez CA, Serna-Ros P, Castro-Bugallo C. Reliability of transfer 496 length estimation from strand end slip. ACI Struct J 2007;104(4):487-494.

497 [9] Russell BW, Burns NH. Measured transfer lengths of 0.5 and 0.6 in. strands in 498 pretensioned concrete. PCI J 1996;41:44-65.

499 [10] AENOR. UNE 36094:1997 Alambres y cordones de acero para armaduras de hormigón 500 pretensado. Madrid: AENOR; 1997.

501 [11] ASTM. A416/A416M-10 Standard specification for steel strand, uncoated seven-wire for 502 prestressed concrete. West Conshohocken, PA: American Society for Testing and Materials; 5032010.

504 [12] Martí-Vargas JR, Serna-Ros P, Fernández-Prada MA, Miguel-Sosa PF, Arbeláez CA. 505 Test method for determination of the transmission and anchorage lengths in prestressed 506 reinforcement. Mag Concr Res 2006;58:21-29.

507 [13] Martí-Vargas JR, Arbeláez CA, Serna-Ros P, Fernández-Prada, MA, Miguel-Sosa PF. 508 Transfer and development lengths of concentrically prestressed concrete. PCI J $509 \quad 2006 ; 51(5): 74-85$.

510 [14] Martí-Vargas JR, Serna-Ros P, Arbeláez CA, Rigueira-Victor JW. Bond behaviour of 511 self-compacting concrete in transmission and anchorage. Mater Constr 2006;56(284):27-42. 512 [15] Caro LA, Martí-Vargas JR, Serna P. Time-dependent evolution of strand transfer length 513 in pretensioned prestressed concrete members. Mech Time-Depend Mater 2012. 514 http://dx.doi.org/10.1007/s11043-012-9200-2. 
515 [16] Caro LA, Martí-Vargas JR, Serna P. Prestress losses evaluation in prestressed concrete 516 prismatic specimens. Eng Struct 2013;48:704-715.

517 [17] Martí-Vargas JR, Serna P, Navarro-Gregori J, Bonet JL. Effects of concrete composition 518 on transmission length of prestressing strands. Constr Build Mater 2012;27:350-356.

519 [18] Briere V, Harries KA, Kasan J, Hager Ch. Dilation behavior of seven-wire prestressing 520 strand - The Hoyer effect. Constr Build Mater 2013;40:650-658.

521 [19] Floyd RW, Howland MB, Hale WM. Evaluation of strand bond equations for prestressed 522 members cast with self-consolidating concrete. Eng Struct 2011;33:2879-2887.

523 [20] Shahawy M, Moussa I, Batchelor B. Strand transfer lengths in full scale AASHTO 524 prestressed concrete girders. PCI J 1992;37:84-96.

525 [21] Mitchell D, Cook WD, Khan AA, Tham Th. Influence of high strength concrete on 526 transfer and development length of pretensioning strand. PCI J 1993;23:52-66.

527 [22] Martí-Vargas JR, Hale WM. Predicting strand transfer length in pretensioned concrete:

528 Eurocode versus North American practice, ASCE J Bridge Eng 2013.

529 http://dx.doi.org/10.1061/(ASCE)BE.1943-5592.0000456 .

530 [23] Mahmoud ZI, Rizkalla SH, Zaghloul ER. Transfer and development lengths of carbon 531 fiber reinforcement polymers prestressing reinforcing. ACI Struct J 1999;96:594-602.

532 [24] Ramirez JA, Russell BW. Transfer, development, and splice length for 533 strand/reinforcement in high-strength concrete. NCHRP Report 603. Washington DC:

534 National Cooperative Highway Research Program, Transportation Research Board; 2008.

535 [25] Gustavson R. Experimental studies of the bond response of three-wire strands and some 536 influencing parameters. Mater Struct 2004;37:96-106.

537 [26] Lorrain M, Khelafi H. Contribution a l'etude de l'endommagement de la liaison 538 armature-beton de haute performance. Mater Struct 1989;22:127-138.

539 [27] Fu X, Chung DDL. Improving the bond strength between steel rebar and 
concrete by increasing the water/cement ratio. Cem Concr Res 1997;27:1805-1809.

541 [28] Król M, Szerafin J. Dynamics of bond development in permanently compressed

542 concrete. In: Bond in concrete: from research to practice. Riga: Ed. Riga Technical University 543 and CEB; 1992, p. 2.47-2.57.

544 [29] Sfikas IP, Trezos KG. Effect of composition variations on bond properties of self-

545 compacting concrete specimens. Constr Build Mater 2013;41:252-262.

546 [30] Pop I, Schutter G, Desnerck P, Onet T. Bond between powder type self-compacting

547 concrete and steel reinforcement. Constr Build Mater 2013;41:824-833.

548 [31] Hegger J, Bertram G. Verbundverhalten von vorgespannten litzen in UHPC. Beton- und 549 Stahlbetonbau 2012;107(1):23-31.

550 [32] Buckner CD. A review of strand development length for pretensioned concrete members.

551 PCI J 1995;40:84-105.

552 [33] CEN. European standard EN 1992-1-1:2004:E: Eurocode 2: Design of concrete 553 structures - Part 1-1: General rules and rules for buildings. Brussels: Comité Européen de 554 Normalisation; 2004.

555 [34] FIB. Model Code 2010. First complete draft - Volume 1.” Fib Bulletin n55. Lausanne:

556 Fédération Internationale du Béton; 2010.

557 [35] Martí-Vargas JR, Serna P, WM Hale. Strand bond performance in prestressed concrete 558 accounting for bond slip. Eng Struct 2013;51:236-244.

559 [36] Martí-Vargas JR, Caro LA, Serna P. Experimental technique for measuring the long-term 560 transfer length in prestressed concrete. Strain 2013;49:125-134.

561 [37] Pozolo A, Andrawes B. Analytical prediction of transfer length in prestressed self562 consolidating concrete girders using pull-out test results. Constr Build Mater 2011;25:10265631036. 
564 [38] Martí-Vargas JR, Arbeláez CA, Serna-Ros P, Navarro-Gregori J, Pallarés-Rubio L.

565 Analytical model for transfer length prediction of $13 \mathrm{~mm}$ prestressing strand. Struct Eng

566 Mech 2007;26:211-229.

567 [39] Ministerio de Fomento. Instrucción de hormigón estructural (EHE-08). Madrid:

568 Ministerio de Fomento; 2008.

569 [40] CEN. European standard EN 197-1:2000: Cement. Part 1: Compositions, specifications

570 and conformity criteria for common cements. Brussels: Comité Européen de Normalisation;

5712000.

572 [41] Fu X, Chung DDL. Effects of water-cement ratio, curing age, silica fume, polymer

573 admixtures, steel surface treatments, and corrosion on bond between concrete and steel

574 reinforcing bars. ACI Mat J 1998;95(6):725-734.

575 [42] Kose MM, Burkett, WR. Formulation of new development length equation for 0.6 in.

576 prestressing strand. PCI J 2005;50(5):96-105. 